\title{
Prospective comparison of costs and short term health outcomes of surgical versus device closure of atrial septal defect in children
}

\author{
M L Hughes, G Maskell, T H Goh, J L Wilkinson
}

Heart 2002;88:67-70

See end of article for authors' affiliations

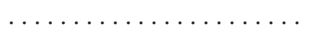

Correspondence to: Marina L Hughes,

Department of Cardiology, Royal Children's Hospital, Flemington Road, Parkville, Victoria 3052, Australia; hughes@cosmos.net.au

Accepted 13 March 2002
Objective: To compare surgical and device closure of isolated secundum atrial septal defect (ASD) in terms of hospital costs, clinical outcome, and impact on the patient and family.

Design: Prospective, observational study.

Setting: Paediatric tertiary referral centre.

Patients: Consecutive local children with a secundum ASD, admitted between 1 May 1999 and 1 May 2001.

Methods: Parents completed a standardised questionnaire at recruitment (on admission), at discharge, and one month after the procedure. Clinical and hospital generated cost data were collated at discharge.

Results: 62 children were included in the analysis: 19 who underwent surgical repair and 43 who underwent device closure with the Amplatzer septal occluder. Median procedure times and hospital stay were significantly longer for surgical patients (170 (147 to 180) v92 (70 to 115$)$ minutes and 88 $(78$ to 112$) \vee 29$ (28 to 30) hours, respectively; $p<0.01)$. There was no difference in the complication rate. No device patients required intensive care or blood products. The median values for postoperative pain score, analgesia use, and convalescence time were greater for surgical patients. The median cost of each procedure was similar, but higher nursing and laboratory costs contributed to a slightly greater total cost for surgical repair (Aus\$12 969 (\$11 569 to \$14 215) v Aus\$11 845 (\$10 669 to $\$ 12555), p=0.03$ ).

Conclusions: Device closure of ASD involves a shorter hospital stay, causes less discomfort and familial disturbance, and carries less cost than surgical closure. However, there should be guarded acceptance of this technique until long term data are available. ju mproved clinical outcome is a necessary but insufficient justification for the replacement of conventional treatment with a new health intervention. Total costs, functional health status, and patient satisfaction also need to be considered, and are prominent in the current debate over the procedure of choice for closure of isolated secundum atrial septal defects (ASD).

In many paediatric cardiac institutions surgical closure is reserved for the patients whose families choose surgical repair or whose lesions remain unsuitable for device closure. ${ }^{1-3}$ Surgical closure of secundum ASD has a high success rate, with low morbidity and a favourable long term outcome. ${ }^{45}$ In comparison, ASD occlusion devices vary in their success, but the closure rate with the Amplatzer septal occluder ${ }^{6}$ (AGA Medical, Golden Valley, Minnesota, USA) is close to $95 \%$ and the morbidity is low. ${ }^{7-11}$ Advantages claimed for device closure include better cosmesis, avoidance of cardiopulmonary bypass, and shorter hospital stay. ${ }^{12}{ }^{13}$ However, there is no long term information about the outcome and safety of the intracardiac prostheses.

We gathered data prospectively from contemporary groups of children who were suitable for either surgical or device closure of secundum ASD. We assessed the impact of each procedure on the patient and their family, and the total cost of device closure relative to surgical closure in a single institution within the Australian health system.

\section{METHODS}

\section{Design}

The study was a prospective observational survey using structured questionnaires.

\section{Subjects}

We recruited consecutive patients from Victoria who were admitted to the Royal Children's Hospital between 1 May 1999 and 1 May 2001 for closure of an isolated secundum ASD. During this time there was no institutional policy for selecting either surgical or device closure for moderate sized central defects of the oval fossa. The treating cardiologist and parents made the decision regarding closure during the outpatient assessment.

\section{Surgical ASD closure}

Surgical ASD closure was undertaken through a limited midline sternotomy $(n=7)$, lower half sternotomy $(n=7)$, or lateral thoracotomy $(\mathrm{n}=5)$, using cardiopulmonary bypass. Closure of the defect was accomplished either directly $(\mathrm{n}=10)$ or with a pericardial patch $(\mathrm{n}=9)$.

Patients recovered in the intensive care unit and were transferred to the cardiology ward after extubation. According to unit protocol, all received intravenous morphine postoperatively for the first 24 hours. Oral codeine and paracetamol were then given as required.

\section{Transcatheter ASD closure}

All transcatheter ASD closures were performed by one of two paediatric cardiac interventionalists, using only the Amplatzer septal occluder. The procedure was carried out under general anaesthesia using previously described methods. ${ }^{14}$ Aspirin was given for three months after device insertion at antiplatelet dosage. 
Table 1 Clinical characteristics of surgical and device patients, shown as median (interquartile range)

\begin{tabular}{llll}
\hline & Device closure & Surgical closure & p Value \\
\hline Number & 43 & 19 & \\
Age (years) & $6.1(3.3-10.0)$ & $3.3(2.0-5.4)$ & 0.008 \\
Body surface area $\left(\mathrm{m}^{2}\right)$ & $0.8(0.66-1.14)$ & $0.62(0.5-0.82)$ & 0.02 \\
Weight $(\mathrm{kg})$ & $20.2(15.2-34.5)$ & $13.9(10.2-19.4)$ & 0.004 \\
ASD on TTE $(\mathrm{mm})$ & $12(10-15)$ & $13.5(12-20)$ & $\mathrm{NS}$ \\
Balloon size $(\mathrm{mm})$ & $18(15-22)$ & & \\
Size of device $(\mathrm{mm})$ & $19(15-22)$ & $17.5(14.5-23.0)$ & \\
Size at surgery $(\mathrm{mm})$ & &
\end{tabular}

\section{Clinical data collection}

Patients were recruited at the time of clerking into the hospital. The parents of each patient completed a standardised questionnaire on admission, at discharge, and at the first outpatient follow up appointment. Clinical information was collated at the time of discharge from hospital.

\section{Cost estimation}

The total cost to the hospital of each patient's admission was calculated using the Royal Children's Hospital's computerised clinical costing system, "Transition II" (Eclipsys, The Outcomes Company, Boca Raton, Florida, USA). This system gives a value to each episode of patient care. The method of costing relies on each service area of the hospital weighting the product or services they provide. Costs from the general ledger are then allocated to these products, based on the weighting. Indirect costs are also allocated to each product, but capital and depreciation costs are not included.

As a result, the system produces an itemised cost report for each patient which includes the costs of the operating theatre and anaesthesia, the cost of the ASD device, surgical and medical fees, nursing care, laboratory investigations, radiology, pharmaceutical costs, and physiotherapy. All values are expressed in Australian dollars.

\section{Statistics}

Results were analysed according to the final successful method of closure for each patient. Non-parametric statistical methods were used. Continuous data were compared using the Mann-Whitney U test and categorical data using Fisher's exact test. The results are expressed as median (interquartile range). A probability value of $p<0.05$ was considered significant.

\section{RESULTS}

\section{Patient demographics}

The results represent 62 children: 19 ( 10 male, 9 female) who underwent closure by surgery and 43 (22 male, 21 female) who underwent closure by device. There was one failed attempt at device closure, with subsequent successful surgery. This child's data were included with those of the surgical patients. Five additional patients were admitted for device closure but found unsuitable during transoesophageal echocardiography in the catheter laboratory. They were excluded from the analysis.

These children were aged from 0.9-17 years, and they weighed from $6.6-78 \mathrm{~kg}$. The largest diameter of the atrial defect on preoperative transthoracic echocardiography ranged from $6-30 \mathrm{~mm}$. Table 1 gives the clinical characteristics of each group. The children undergoing surgical closure were significantly younger and smaller than those undergoing device closure, though the diameter of the defects in each group was similar.

\begin{tabular}{|c|c|c|c|}
\hline & Device closure & Surgical closure & $\mathrm{p}$ Value \\
\hline Number & 43 & 19 & \\
\hline Anaesthetic time (min) & $92(70-115)$ & $170(147-180)$ & $<0.01$ \\
\hline ICU stay (hours) & 0 & $20(18-21)$ & - \\
\hline Hospital stay (hours) & $29(28-30)$ & 88 (78-112) & $<0.01$ \\
\hline $\begin{array}{l}\text { Post-procedure pain } \\
\text { score }\end{array}$ & $1.2(0.4-3.0)$ & $4.9(3.1-7.7)$ & $<0.001$ \\
\hline Analgesia after 48 hours & $0 / 43$ & $13 / 19(68 \%)$ & $<0.001$ \\
\hline
\end{tabular}

Table 3 Complications of surgical and device closure in the study cohort

\begin{tabular}{lc}
\hline Surgical closure & Device closure \\
\hline - $1 \times$ wound infection & $-1 \times$ failure to implant $(6 \mathrm{~kg}$ child) \\
Readmission to hospital & Left embolic cerebrovascular accident \\
Surgical exploration & $-1 \times$ supraventricular tachycardia \\
- $1 \times$ sternal wire fracture & Reverted with adenosine \\
Repeat sternal closure & $-5 \times>1$ device deployed in same \\
& procedure \\
& Final deployment successful \\
\hline
\end{tabular}

\section{Procedural factors}

A comparison of the procedural aspects of all patients studied is shown in table 2. Children undergoing device closure experienced a shorter duration of anaesthesia, a shorter inpatient stay, required analgesia for a shorter period, and had a lower postoperative pain score than surgical patients. Six children in the surgical group $(<12 \mathrm{~kg})$ required packed blood cells for the cardiopulmonary bypass prime. Blood products were not required by any patient in the device group. Complications occurring in the two groups are listed in table 3.

\section{Recovery}

By the first post-procedural day, 1/19 surgical patients and 14/43 device patients had resumed preadmission physical activity levels $(p<0.01)$, and by one week these proportions were $4 / 19$ and $36 / 43$, respectively $(p<0.01)$.

At the time of discharge more parents of children in the surgical group than in the device group were concerned about the tenderness or vulnerability of their child's wound (10/19 v 4/43, respectively; $\mathrm{p}<0.01$ ).

\section{Efficacy}

Echocardiographic evaluation three months after the procedure showed a small residual shunt in four patients in the 


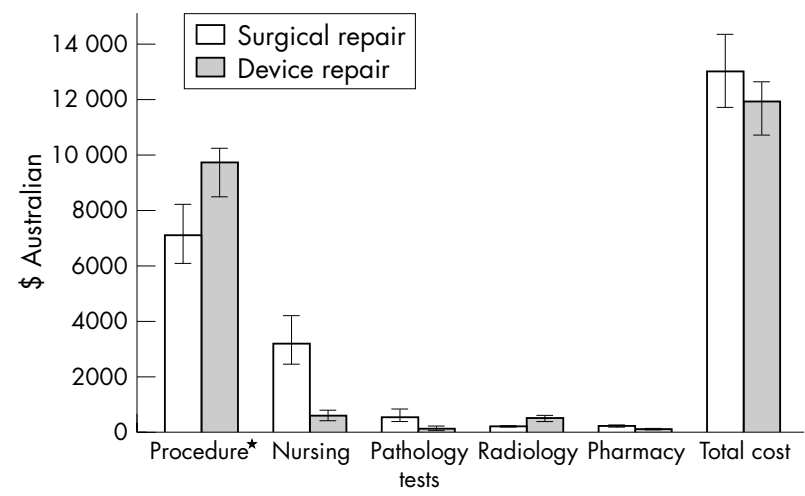

Figure 1 Comparison of median cost (with interquartile range) of ASD closure: itemised and total. *Includes the cost of the theatre or catheter laboratory, anaesthetic, and Amplatzer septal occluder.

device group (complete closure rate $91 \%$ ). No patient had a residual shunt in the surgical group $(\mathrm{p}=0.3)$.

\section{Satisfaction}

Approximately one third of both groups of parents were concerned about the long term outcome of the procedure. Parents of children in the surgical group were worried about the invasiveness of the procedure, the effects of cardiopulmonary bypass, and the residual scar. Parents of children in the device group expressed concerns about dislodgement of the device and the long term safety of the device.

\section{Family costs}

Fathers of children undergoing surgical closure took a median of four days off work, versus one day taken by fathers of those undergoing device closure. There was no significant difference in the amount of leave taken by mothers.

\section{Hospital costs}

Figure 1 is a simplified account of the median hospital cost of surgical and device closure for the individuals in the study. Procedural costs (theatre + anaesthetic + device as applicable) were less for surgical closure than for device closure. However, the requirement for intensive care and the longer hospital stay caused greater nursing, laboratory, and pharmacy costs to contribute to a slightly greater total cost for surgical repair (Aus\$12 969 (\$11 569 to \$14 215) v Aus\$11 845 (\$10 669 to $\$ 12555)$ ).

\section{DISCUSSION}

Though transcatheter device closure may be appropriate treatment for secundum ASD, there has never been a truly randomised comparison of device and conventional surgical repair.

This is a prospective assessment of children with isolated, moderate sized, central defects of the oval fossa, who were potential candidates for either surgical or device repair. We examined contemporary study groups and completed the study four years after device repair was initiated in our institution,${ }^{14}$ minimising any learning curve effects.

While the above factors should diminish bias in the comparison, there were fewer patients in the group undergoing surgery, and they were significantly younger and smaller than the group undergoing device repair. This dissimilarity between the groups is unlikely to affect the cost of repair, but the median size of the atrial defects in each group was similar, possibly indicating proportionally larger lesions in the surgical group.
The age and weight differences between our study groups indicate a bias towards surgical treatment for younger and smaller children. This is supported by cautionary evidence in published reports, ${ }^{15}$ and by the fact that a major complication occurred in the smallest and youngest child in the device group of our study. A current priority should be the improvement of our ability to select patients appropriately for device closure.

We have contributed to contemporary data by assessing a broad range of short term outcomes, but importantly this is the first prospective analysis of the cost of device versus surgical closure of ASD in the Australian health care system. The major area of cost savings to the hospital is in elimination of the requirement for intensive care, and the greatly reduced length of hospital admission. However, the significant cost of the device itself may alter the balance of costs in different health care systems, particularly in less industrialised nations. Recently published abstracts show that transcatheter closure of an ASD carries a substantial cost advantage in Switzerland, ${ }^{16}$ but surgical closure appears to carry a cost advantage in the UK and Thailand..$^{17}$

\section{Conclusions}

In a paediatric population, device closure of an isolated secundum ASD carries many short term advantages for the patient, family, and the treating hospital. However, final judgement in comparison with conventional surgical treatment will not be possible until long term outcome data are available.

\section{Authors' affiliations}

M L Hughes, G Maskell, T H Goh, J L Wilkinson, Department of Cardiology, Royal Children's Hospital, Melbourne, Australia

\section{REFERENCES}

1 Berger F, Vogel M, Alexi-Meskishvili V, et al. Comparison of results and complications of surgical and Amplatzer device closure of atrial septal defects. I Thorac Cardiovasc Surg 1999:118:674-8.

2 Wilkinson JL. Can transcatheter closure of atrial septal defect be regarded as a "standard" procedure? Cardiol Young 1999;9:458-61.

3 Rao PS. Transcatheter closure of atrial septal defect: are we there yet? J Am Coll Cardiol 1998:31:1117-19.

4 Meijboom F, Hess J, Szatmari A, et al. Long-term follow-up (9 to 20 years) after surgical closure of atrial septal defect at a young age. Am J Cardiol 1993;72:1431-4.

5 Murphy JG, Gersh BJ, McGoon MD, et al. Long-term outcome after surgical repair of isolated atrial septal defect. N Engl J Med 1990;323: 1645-50

6 Bjornstad PG, Masura J, Thaulow E, et al. Interventional closure of atrial septal defects with the Amplatzer device: first clinical experience. Cardiol Young 1997; 7:277-83.

7 Chan KC, Godman M, Walsh K, et al. Transcatheter closure of atrial septal defect and interatrial communications with a new self expanding nitinol double disc device (Amplatzer septal occluder): multicentre UK experience. Heart 1999;82:300-6

8 Walsh KP, Tofeig M, Kitchiner DJ, et al. Comparison of the Sideris and Amplatzer septal occlusion devices. Am J Cardiol 1999;83:933-6.

9 Formigari R, Santoro G, Rossetti L, et al. Comparison of three different ASD occlusion devices. Am J Cardiol 1998;82:690-2.

10 Godart F, Rey C, Francart C et al. Experience in one centre using the buttoned device for occlusion of atrial septal defect: comparison with the Amplatzer septal occluder. Cardiol Young 2000;10: 527-33.

11 Berger F, Ewert P, Bjornstad PG et al. Transcatheter closure as standard treatment for most interatrial defects: experience in 200 patients treated with the Amplatzer septal occluder. Cardiol Young 1999;9:468-73.

12 Formigari R, Di Donato RM, Mazzera E, et al. Minimally invasive or interventional repair of atrial septal defects in children: experience in 171 cases and comparison with conventional strategies. J Am Coll Cardiol 2001;37:1707-12.

13 Cowley CG, Lloyd TR, Bove EL et al. Comparison of results of closure of secundum atrial septal defect by surgery versus Amplatzer septal occluder. Am J Cardiol 2001:88:589-91.

14 Wilkinson JL, Goh TH. Early clinical experience with use of the "Amplatzer septal occluder" device for atrial septal defect. Cardiol Young 1998;8:295-302.

15 Vogel M, Berger F, Dahnert I, et al. Treatment of atrial septal defects in symptomatic children aged less than 2 years of age using the Amplatzer septal occluder. Cardiol Young 2000; 10:534-7. 
16 Galal MO, von Bremen K, Sekarski N, et al. Cost-comparison of transcatheter and surgical closure of atrial septal defect in children [abstract]. Proceedings of the 3rd World Congress of Pediatric Cardiology and Cardiac Surgery, Toronto, Canada, 2001:878.

17 Thomson JDR, Aburawi $\mathrm{H}$, Watterston KG, et al. Transcatheter (Amplatzer) versus surgical closure of ASD: a prospective comparison of results and cost [abstract]. Proceedings of the 3rd World Congress of
Pediatric Cardiology and Cardiac Surgery, Toronto, Canada, 2001:913

18 Duronpisitkul K, Soongswang J, Laohaprasitiporn D, et al. Comparison of atrial septal defect closure using Amplatzer septal occluder with surgery [abstract]. Proceedings of the 3rd World Congress of Pediatric Cardiology and Cardiac Surgery, Toronto, Canada, 2001:830

\section{IMAGES IN CARDIOLOGY}

\section{Bilateral origin of a split left anterior descending coronary artery combined with atypical branching of the left circumflex coronary artery}

A

51 year old diabetic presented with a five hour history of severe chest pain at a community hospital. The ECG showed an acute anterolateral wall myocardial infarction and the patient was treated with intravenous tissue plasminogen activator (t-PA). Because of postinfarction angina, he was referred for coronary angiography.

Selective coronary angiography revealed an unusual coronary artery anomaly. The dominant right coronary artery (RCA) arose from the appropriate sinus of Valsalva. However, an ectopic left anterior descending coronary artery (LAD) was seen to originate from the proximal part of the right coronary artery (see diagram: RCA, right coronary artery; RVB, right ventricular branch; $S$, septal artery; LAD, left anterior descending artery; LCx, left circumflex artery. Interrupted lines indicate intramural course). After giving off a small right ventricular branch, the ectopic LAD passed intramuscularly through the interventricular septum before reaching an epicardial position at the mid septum. Within the septum, the ectopic LAD formed a caudal-anterior loop which gave a characteristic "hammock" appearance in the RAO projection (video sequence 1 , freeze frame below diagram). Later, the ectopic LAD began its descent in the anterior interventricular groove adjacent to a $180^{\circ}$ loop in a second LAD (see below), which originated from the left sinus of Valsalva.

This second LAD originating from the left anterior sinus of Valsalva ran in the proximal third of the interventricular groove and gave rise to a large, diffusely diseased diagonal branch. Later, the LAD gave off a small septal branch, and then turned upward in a $180^{\circ}$ loop which contained a subtotal stenosis. This ascending part of the LAD, an anomalous origin of the left circumflex artery (LCX), proceeded to cross the diagonal branch and then entered the AV groove where it divided into two branches supplying the lateral wall of the left ventricle (video sequences 2 and 3 , freeze frames in right hand column). Thus, the proximal LAD followed a highly anomalous course into the LCX.

All coronary arteries showed diffuse narrowings in their distal segments. The subtotal
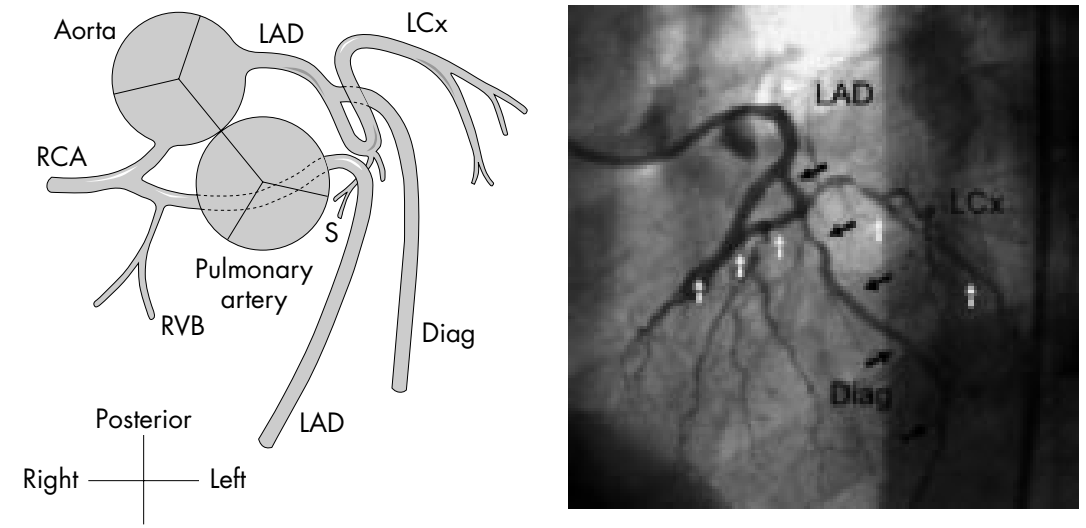

Anterior
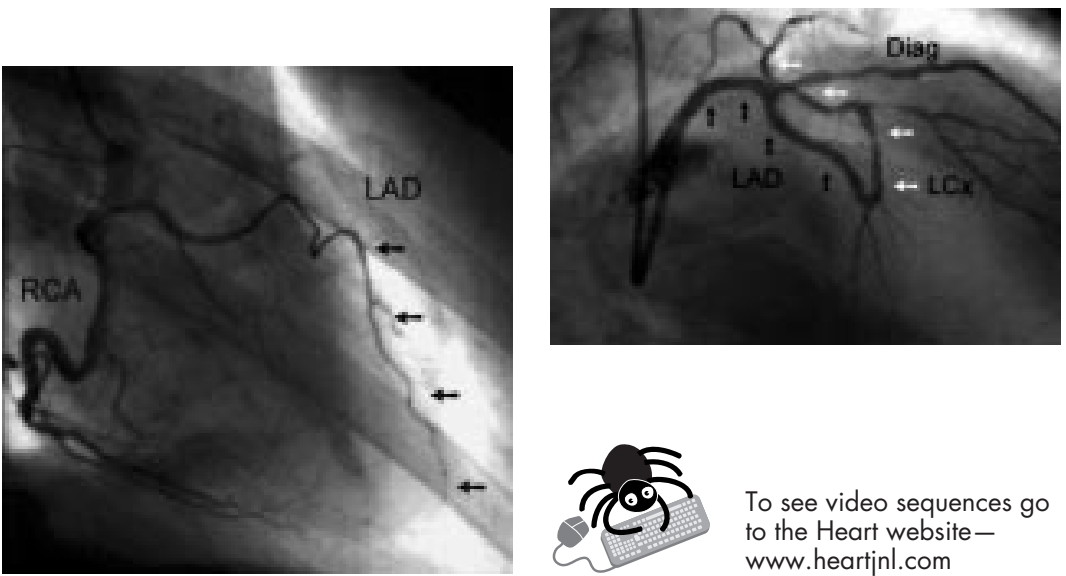

stenosis in the $180^{\circ}$ loop of the anomalous LAD-LCx transition was successfully treated by angioplasty.

Coronary artery anomalies occur in 0.2 $1.2 \%$ of the population. The most common anomalies involve either a retro-aortic coursing LCx arising from the right coronary cusp or the RCA, or alternatively an RCA arising from the left coronary cusp. These two anomalies account for $72 \%$ of all coronary artery anomalies. The LAD originates from 